\title{
Effect of etching time and light sources on the shear bond strength of metal brackets to ceramic cylinders
}

\author{
Efeito do tempo de condicionamento e de fontes de luz na resistência ao cisalhamento de braquetes me- \\ tálicos colados ao cilindro de cerâmica
}

\author{
Magda Regina PIAIA ${ }^{1}$ \\ Ana Rosa COSTA2 \\ Américo Bortolazzo CORRER² \\ LourençO CORRER-SOBRINHO² \\ Ivana Uglik GARBUI' \\ Paulo Roberto Aranha NOUER'
}

\section{ABSTRACT}

\section{Objective}

To evaluate the shear bond strength of brackets bonded to ceramic with Transbond XT resin, etching time intervals (1 and 2 minutes) and three Light sources (Xenon Plasma ArC, LED and Halogen Light), with and without silane.

\section{Methods}

In total, 12 feldspathic ceramic cylinders $(15 \mathrm{~mm} \times 20 \mathrm{~mm})$, etched with 10\% hydrofluoric acid were used. For light activation, the brackets were divided according to the light source to be used (n-15): LED UltraLume 5 (L); Apollo $95 E$ plasma arc (AP) and Halogen light XL 2500 (H). After $24 \mathrm{~h}$ the samples were submitted to shear bond strength testing at crosshead speed of $0.5 \mathrm{~mm} / \mathrm{minute}$.

\section{Results}

The data were submitted to the analysis of variance (ANOVA) and the Tukey test (5\%). Bond Strength: UltraLume 5 (11.4 $\pm 3.56 \mathrm{MPa})$ was superior to XL 2500 (9.12 $\pm 2.83 \mathrm{MPa})$ and Plasma Arc $(5.11 \pm 2.93 \mathrm{MPa})(p<0.05)$. No difference was found between ceramic with silane $(8.31 \pm 4.17 \mathrm{MPa})$ and without silane $(8.68 \pm 3.86 \mathrm{MPa})$. Etching time of 2 minutes $(9.13 \pm 3.98 \mathrm{MPa})$ was superior to time of $1 \mathrm{minute}(7.86$ $\pm 3.96 \mathrm{MPa})$.

\section{Conclusion}

The results showed that LED was shown to be more efficient for polymerizing the material for Transbond XT bonding. The use of silane did not influence the bond strength values. The acid etching time of 2 minutes was more effective than that of 1 minute.

Indexing terms: Orthodontic brackets. Orthodontics. Shear strength.

\section{RESUMO}

Objetivo

Avaliar a resistência de união ao cisalhamento de braquetes colados à cerâmica com a resina Transbond XT nos tempos de condicionamento (1 e 2 minutos) e três fontes de Luz (Arco de Plasma e Xenônio, LED e Luz de lâmpada halógena), com e sem silano.

\section{Métodos}

Foram utilizados 12 cilindros de cerâmica feldspática $(15 \mathrm{~mm}$ x $20 \mathrm{~mm}$ ), condicionados com ácido fluorídrico 10\%. Para a fotoativação, os braquetes foram separados de acordo com a fonte de luz a ser utilizada ( $n=15)$ : LED UltraLume 5 (L), arco de plasma Apollo 95E (AP) e luz de lâmpada halógena XL 2500 (H). Após 24 h, as amostras foram submetidas ao ensaio de resistência de união ao cisalhamento a velocidade de $0,5 \mathrm{~mm} /$ minuto.

\section{Resultados}

Os dados foram submetidos à Analise de Variância e ao teste de Tukey (5\%). Resistência de união: Ultralume 5 (11,24 $\pm 3,56 \mathrm{MPa})$ foi superior ao XL $2500(9,12 \pm 2,83 \mathrm{MPa})$ e Arco de Plasma (5,11 $\pm 2,93 \mathrm{MPa})(\mathrm{p}<0,05)$. Nenhuma diferença foi encontrada entre a cerâmica com silano $(8,31 \pm 4,17 \mathrm{MPa})$ e sem silano $(8,68 \pm 3,86 \mathrm{MPa})$. O tempo de condicionamento de 2 minutos $(9,13 \pm 3,98 \mathrm{MPa})$ foi superior ao tempo de 1 minuto $(7,86 \pm 3,96 \mathrm{MPa})$.

\section{Conclusão}

Os resultados mostraram que o LED mostrou-se mais eficiente para polimerizar o material para colagem Transbond XT. O uso do silano não influenciou os valores de resistência de união. O tempo de condicionamento ácido de 2 minutos foi mais efetivo que 1 minuto.

Termos de indexação: Braquetes ortodônticos. Ortodontia. Resistência ao cisalhamento.

\footnotetext{
${ }^{1}$ Faculdade São Leopoldo Mandic, Curso de Odontologia, Departamento de Ortodontia. Rua José Rocha Junqueira, 13, Swift, 13045-755, Campinas, SP, Brasil. Correspondência para / Correspondence to: PRA NOUER. E-mail: <nouerp3@gmail.com>.

${ }^{2}$ Universidade Estadual de Campinas, Faculdade de Odontologia, Departamento de Odontologia Restauradora. Piracicaba, SP, Brasil.
} 


\section{INTRODUCTION}

Over the last few years, in addition to bonding to tooth enamel, there has been an increase in bonding to dental ceramics due to the high number of patients who have ceramic restorations. This has led to demanding that orthodontist have the capacity and knowledge of some methods for adequate bonding of brackets to this substrate 1 .

Materials are bonded to ceramic surfaces after etching with hydrofluoric acid ${ }^{2-4}$. The use of hydrofluoric acid has not been shown to be efficient for creating retentions for bonding to Dental ceramics ${ }^{2-3,5}$. However, with the aim of simplifying the techniques for the purpose of reducing the time necessary for the procedures, some professionals have varied the time of hydrofluoric acid application during the clinical procedure. For bracket bonding, little is known about the influence of etching time on the bond strength to ceramic. The literature has shown conflicting results, such as those of Barghi et al. ${ }^{6}$ and Shimada et al. ${ }^{7}$, who have shown that an increase in exposure time could reduce the bond strength. Whereas, Chen et al. ${ }^{8}$ and Güller et al. ${ }^{9}$ observed that by increasing the etching time, higher bond strength values to ceramic have been found.

Furthermore, it is important to consider the application of silane, a monomeric substance composed of reactive organic radicals and hydrolyzable monovalent groups on the ceramic surface. This procedure has made it possible to bond ceramic artificial teeth to the acrylic resin denture base of complete dental prostheses ${ }^{10-11}$. Rosentiel et al. ${ }^{12}$ have shown that silane increased the bond between glass ionomer cement and dental ceramic.

Another factor to be taken into consideration are the light activating appliances used for polymerizing the bonding material. In spite of quartz and tungsten halogen lamps having been the first to be used in Dentistry ${ }^{13}$, the light obtained with these appliances present a broad spectrum of emission, so that filters are needed to limit the emission spectrum between 400 and $500 \mathrm{~nm}$. Recently, light emitting diode appliances (LED) have become popular, particularly due to their long useful life. They have a narrow light emission spectrum in comparison with the halogen lamp, ranging between 450 and $500 \mathrm{~nm}^{13}$.

In addition to the above-mentioned light sources, there are other appliances available for light activation, with different characteristics from those previously mentioned, such as the plasma arc that emits light from a gaseous mixture of ionized molecules and electrons at high temperatures ${ }^{14-16}$. The light emitted by this appliance has high irradiance, and may reduce the time necessary for light activation of resin materials.

As the literature is inconclusive with regard to the time necessary for the arcs to be installed, or tied to the brackets, the aim of this study was to evaluated the shear bond strength of metal brackets bonded to dental ceramic with Transbond XT resin, after etching with hydrofluoric acid for 1 and 2 minutes, and light activated with Xenon Plasma Arc, LED and Halogen lamp light, either with or without silane application. After removal of the brackets, the Adhesive Remnant Index (ARI) was evaluated.

\section{METHODS}

Twelve feldspathic ceramic cylinders (Certec Advanced Ceramics, Barueri, Brazil), measuring $15 \mathrm{~mm}$ in diameter by $20 \mathrm{~mm}$ high were used in this study. The surfaces of all the cylinders were cleaned with pumice stone and water before the test. Six cylinders were etched with $10 \%$ hydrofluoric acid for 1 minute and six for 2 minutes (Dentsply Caulk, Milford, DE, USA). After etching, the surface was washed for 20 seconds and dried for 20 seconds. On half of the cylinders, 2 layers of the silanization agent RelyX Ceramic Primer (3M, ESPE, St.. Paul, MN, USA) were applied and dried for 10 seconds. The stainless steel Edgewise Standard brackets, slot 0,022" (Dental Morelli, Sorocaba, Brazil) were bonded to the ceramic cylinder surfaces using Transbond XT (3M Unitek, Monrovia, CA, USA), in accordance with the manufacturer's recommendations (Chart 1).

The brackets were firmly placed on the ceramic surface. Excess resin cement was removed with a clinical probe, and irradiation was performed using one of the three light sources (Table 1). The irradiance emitted by each light source was checked with a power meter (Ophir Optronics Inc., Danvers, MA, USA) and the emission spectrum was obtained with the light spectrometer controlled by computer (USB 2000; Ocean Optics, Dunedin, FL, USA). After bracket bonding, the test specimens were stored in deionized water at $37^{\circ} \mathrm{C}$ for 24 hours. A total of 15 test specimens were fabricated for each type of light activating appliance, etching time and specimens with or without silane application, totaling 180 brackets bonded. 
Chart 1. Division of the twelve groups $(n=15)$ studied, according to light activating appliances, etching time and with or without silane application.

\begin{tabular}{|lcccc|}
\hline Groups & $\begin{array}{c}\text { Light activating } \\
\text { appliances }\end{array}$ & $\begin{array}{c}\text { Etching } \\
\text { time }\end{array}$ & Silane & $\begin{array}{c}\text { Groups } \\
\text { Abbrev. }\end{array}$ \\
\hline 1 & XL 2500 & 1 minute & With & S1H \\
2 & XL 2500 & 1 minute & Without & NS1H \\
3 & LED - UltraLume 5 & 1 minute & With & S1L \\
4 & LED - UltraLume 5 & 1 minute & Without & NS1L \\
5 & Apollo 95E & 1 minute & With & S1A \\
6 & Apollo 95E & 1 minute & Without & NS1A \\
7 & XL 2500 & 2 minutes & With & S2H \\
8 & XL 2500 & 2 minutes & Without & NS2H \\
9 & LED - UltraLume 5 & 2 minutes & With & S2L \\
10 & LED - UltraLume 5 & 2 minutes & Without & NS2L \\
11 & Apollo 95E & 2 minutes & With & S2H \\
12 & Apollo 95E & 2 minutes & Without & NS2H \\
\hline
\end{tabular}

Table 1. Characteristics of light activating appliances used in study

\begin{tabular}{lllll}
\hline Appliance & $\begin{array}{l}\text { Light } \\
\text { Source }\end{array}$ & Irradiance & $\begin{array}{l}\text { Energy } \\
\text { Density }\end{array}$ & Manufacturer \\
\hline XL 2500 & $\begin{array}{l}\text { Halogen } \\
\text { Lamp }\end{array}$ & $800 \mathrm{~mW} / \mathrm{cm}^{2}$ & $20 \mathrm{~J} / \mathrm{cm}^{2}$ & 3 3M ESPE \\
UltraLume 5 & LED & $1500 \mathrm{~mW} / \mathrm{cm}^{2}$ & $48 \mathrm{~J} / \mathrm{cm}^{2}$ & Ultradent \\
Apollo 95E & $\begin{array}{l}\text { Plasma } \\
\text { arc }\end{array}$ & $1200 \mathrm{~mW} / \mathrm{cm}^{2}$ & $12.4 \mathrm{~J} / \mathrm{cm}^{2}$ & DMD \\
& & & & \\
\hline
\end{tabular}

After the storage period, the ceramic cylinder was fixed to the bottom vise of the Instron universal mechanical test machine (Corp. Model 4411, Mass. (USA) The chisel-shaped active tip was adapted to the ceramic/bracket interface, fixed to the top mobile vise, and the shear bond strength test was performed at a compression speed of $0.5 \mathrm{~mm} /$ minute. The position of the set in the vises allowed the compression movement to be performed parallel to the ceramic cylinder, impressing the shear force on the ceramic/bracket interface, in an endeavor to simulate the force that normally occurs in the oral medium during the mechanical forces for tooth movement. The bond strength values were calculated in Mpa. The numerical bond strength values were submitted to two-way Analysis of Variance and Tukey tests $(\mathrm{P}<0.05)$.

The adhesive remnant index (ARI) was evaluated at 40x magnification under a stereoscopic loupe (Carl Zeiss). The base if each bracket and the ceramic cylinder surface were observed, and the failure patterns classified in accordance with the scores of Pignatta et al. ${ }^{17}: 1$ ) all the adhesive on the tooth; 2)over $90 \%$ of the adhesive on the tooth; 3 ) over $10 \%$ and less than $90 \%$ of the adhesive on the tooth; 4) less than $10 \%$ of the adhesive on the tooth; and, 5) none of the adhesive on the tooth.

\section{RESULTS}

Statistical analysis showed that the factor light source was significant $(p<0.001)$, showing that the bond strength for UltraLume 5 (11.24 MPa) was significantly higher than it was for the XL 2500 (9.12 MPa) and Plasma Arc (5.11 MPa) appliances. The XL2500 appliance was significantly superior to the Plasma Arc appliance (Table 2). Figure 1 shows the emission spectrum of the 3 light sources. The XL 2500 and Plasma Arc light appliances showed a broad spectrum of light, while the UltraLume 5 (LED) showed a narrow peak of emission. The factor etching was significant $(p=0.004)$, with the samples etched for 2 minutes $(9.13 \mathrm{MPa}$ ) presenting significantly higher values to those etched for 1 minute $(7.86 \mathrm{MPa}$ ) (Table $3)$. The factor silane was not significant $(p=0.344)$. No statistical difference was observed between the surfaces that received silane application (8.31 $\mathrm{MPa}$ ) and those without application (8.68 MPa) (Table 4). The results of the Adhesive Remnant Index (ARI) showed that there was a predominance of Score 5 (no residual resin on ceramic) for all the groups, except for Groups S1A, in which there was predominance of Score 1.

Table 2. Mean bond strength values (MPa) of brackets bonded to feldspathic ceramic, considering light source, irrespective of surface treatment and etching time.

\begin{tabular}{lcc}
\hline Light Source & \multicolumn{2}{c}{ Bond Strength (MPa) } \\
\hline UltraLume 5 (LED) & $11.24(3.56)$ & $\mathrm{a}$ \\
XL 2500 (Halogen light) & $9.12(2.83)$ & $\mathrm{b}$ \\
Plasma arc & $5.11(2.93)$ & $\mathrm{c}$ \\
\hline
\end{tabular}

Note: Different letters indicate statistically significant differences $(p<0.05)$ ( ) Standard Deviation

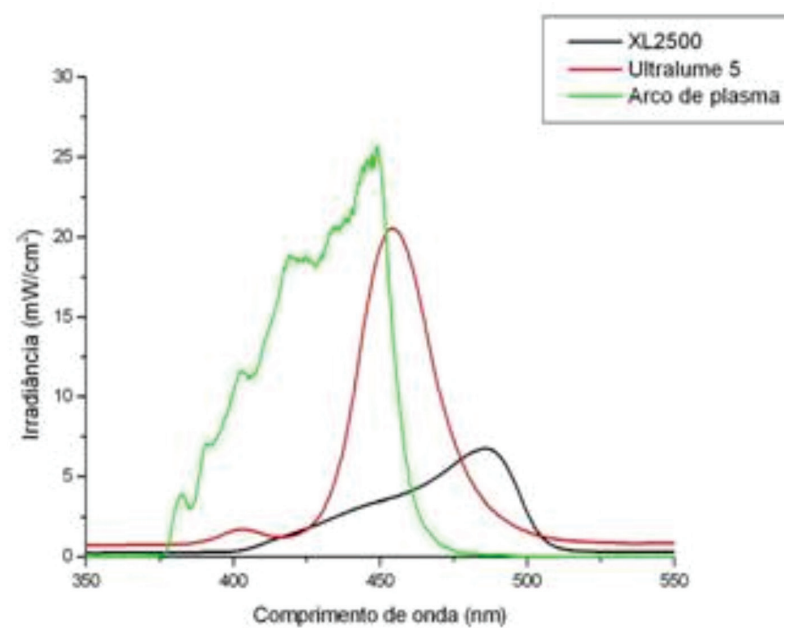

Figure 1. Emission spectra of different Light Sources 
Table 3. Mean bond strength values (MPa) of brackets bonded to feldspathic ceramic, considering etching time, irrespective of use of silane or without silane, and light source (MPa).

\begin{tabular}{lll}
\hline Etching time & \multicolumn{2}{c}{ Bond Strength (MPa) } \\
\hline 1 minute & $7.86(3.96)$ & $\mathrm{b}$ \\
2 minutes & $9.13(3.98)$ & $\mathrm{a}$ \\
\hline
\end{tabular}

Note: Different letters indicate statistically significant differences $(p<0.05)$. ( ) Standard Deviation

Table 4. Mean bond strength values (MPa) of brackets bonded to feldspathic ceramic, considering use of silane and without silane use, irrespective of light source and acid etching time.

\begin{tabular}{lcc}
\hline Treatment & \multicolumn{1}{c}{ Bond Strength (MPa) } \\
\hline Silane & $8.31(4.17)$ & a \\
Without Silane & $8.68(3.86)$ & a \\
\hline
\end{tabular}

Note: Similar letters present no statistically significant differences $(p<0.05)$. ( ) Standard Deviation

\section{DISCUSSION}

The results of the study showed that the light source had a significant influence on the bond strength. Some studies have shown that for adequate polymerization of composites the supply of sufficient energy density is necessary ${ }^{18}$. Energy density is the product of irradiance by the time of exposure to light. The irradiances and emission spectra of light sources are described in Table 1 and Figure 1. The light activation time for LED and Halogen Lamp was 40 seconds, distributed into fractions of 10 seconds for each surface (mesial, distal, incisal and cervical). For the Xenon Plasma arc, the exposure time was 12 seconds, being divided into 3 seconds for each surface.

According to Thind et al. ${ }^{19}$ there was no significant difference in light activation of composites for bracket bonding using different light sources. However, among the appliances used in this study, the samples light activated with LED presented significantly higher bond strength values than those light activated with Halogen lamp and plasma arc (Table 2). The energy density values supplied by the Halogen lamp, LED and plasma arc were: $20 \mathrm{~J} / \mathrm{cm}^{2}$, $48 \mathrm{~J} / \mathrm{cm}^{2}$ and $14.4 \mathrm{~J} / \mathrm{cm}^{2}$ respectively. Therefore, the best bond strength values may be related to the more effective polymerization of the samples light activated with LED, due to the higher energy density supplied by these appliances, followed by the Halogen lamp and plasma arc. The lower values of the plasma arc may be related to the lower energy density emitted by these appliances, producing composites with insufficient polymerization ${ }^{18}$. These results corroborate those from the study of Peutzfeldt et al. ${ }^{16}$ who found significant differences in light activation among different light sources, with these results being related to the lower energy density of this light source. It has been suggested that minimum bond strength values to guarantee clinical success in bracket bonding should be between 6 and 8 $\mathrm{MPa}^{20}$. In accordance with these requisites, the bond strength values obtained with plasma arc were below the recommended minimum. However, these values must not be taken as absolute reference, because they are not based on evidence, in spite of being frequently cited.

The use of silane before the cementation of indirect restorations $s^{4,21}$ or bracket bonding ${ }^{5}$ to ceramic surfaces is recommended as an essential factor to guarantee greater interaction between the ceramic and resin materials. The results of this study showed that there was no significant difference between the samples with and without silane application (Table 4) corroborating the results obtained by Peumans et al., ${ }^{3}$ in which the application of silane and the hydrophobic adhesive had no significant effect on the bond strength. However, the bond strength results obtained after silanization must be interpreted with caution, because differences in composition, form of presentation and storage of silane may significantly influence the ceramic/composite bond ${ }^{22-23}$. Therefore, the conclusions with regard to the use of silane must not be generalized for all types of silane. Nevertheless, they must be a questionable part during the treatment of ceramics before being bonded to composites ${ }^{3}$.

Whereas, the etching time with hydrofluoric acid had a significant influence on bond strength. The results showed that the etching time of 2 minutes was significantly superior to that of 1 minute (Table 3 ). In 1998, Chen et. al. ${ }^{8}$ verified that the increase in acid etching time in ceramics from 0 to 2 minutes, increased the bond strength values between resin and ceramic. This increase in bond strength values corresponds to the microstructural changes in the ceramic surface promoted by the longer time of acid etching 8 . According to Yen et al. ${ }^{23}$, the hydrofluoric acid reacts preferentially with the silica of feldspathic ceramic, forming hexafluorsilicates, promoting demineralization of the ceramic surface and the formation of microretentions. In addition to the reaction with the silica of feldspathic ceramic, the acid attacks the vitreous phase of the material, exposing areas of crystals and creating micropores ${ }^{23}$. The increase in etching time, within a certain limit, promotes greater contact surface between the adhesive and ceramic material, improving the interlocking between the materials. Moreover, it is worth emphasizing that acid etching of ceramic depends on the leucite content of the ceramic, as well as the 
type of etching used. According to Barghi et al. ${ }^{6}$, the acid etching time of ceramic depends on the presence of additional leucite crystals. However, very long etching times with hydrofluoric acid may promote the formation of deep channels, pores and precipitates on the ceramic surface, reducing the cohesive strength of the ceramic and harming the interaction with other materials ${ }^{24}$.

Thus, as observed in this study, the use of LED with higher irradiance must be recommended to guarantee greater effectiveness of polymerization of resin materials, in addition to etching with hydrofluoric acid for 2 minutes, because it is more effective. On the other hand, thee results did not take into consideration the effect of storage time and thermal alterations in the bonding of resin materials to ceramic. Therefore, additional clinical and laboratory studies are necessary to complement the results of this study.

\section{REFERENCES}

1 Kitayama Y, Komori A, Nakahara R. Tensile and shear bond strength of resin-reinforced glass ionomer cement to glazed porcelain. Angle Orthod. 2003;73(4):451-6.

2. Kato $H$, Matsumura $H$, Atsuta M. Effect of etching and sandblasting on bond strength to sintered porcelain of unfilled resin. J Oral Rehabil 2000;27(2):103-10. doi: 10.1046/j.13652842.2000.00489.x.

3. Peumans M, Hikita K, De Munck J, van Landuyt K, Poitevin A, Lambrechts $\mathrm{P}$, et al. Effects of ceramic surface treatments on the bond strength of an adhesive luting agent to CAD-CAM ceramic. J Dent. 2007;35(4):282-8. doi: 10.1016/j.jdent.2006.09.006.

4. Simonsen RJ, Calamia JR. Effect coupling agents on bond strength of etched porcelain [abstract]. J Dent Res. 1983;62:297.

5. Ajlouni R, Bishara SE, Oonsombat C, Soliman M, Laffoon J. The effect of porcelain surface conditioning on bonding orthodontic brackets. Angle Orthod. 2005;75(5):858-64.

6. Barghi N, Fischer DE, Vatani L. Effects of porcelain leucite content, types of etchants, and etching time on porcelaincomposite bond. J Esthet Restor Dent. 2006;18(1):47-52. doi: 10.2310/6130.2006.00001.

7. Shimada $Y$, Yamaguchi S, Tagami J. Micro-shear bond strength of dual-cured resin cement to glass ceramics. Dent Mater. 2002;18(5):380-8. doi: 10.1016/S0109-5641(01)00054-9.

8. Chen $J H$, Matsumura $H$, Atsuta M. Effect of different etching periods on the bond strength of a composite resin to a machinable porcelain. J Dent 1998;26(1):53-8. doi: 10.1016/ S0300-5712(96)00078-4.

9. Güller AU, Yilmaz F, Yenisey M, GÃller E, Ural C. Effect of acid etching time and a self-etching adhesive on the shear bond strength of composite resin to porcelain. J Adhes Dent. 2006;8(1):21-5.

\section{CONCLUSION}

Within the limitations of this study, analysis of the results allowed one to conclude that LED was shown to be more efficient for polymerizing the material for bonding with Transbond XT. The use of silane did not influence the bond strength values, and the acid etching time of 2 minutes was more effective than that of 1 minute. Analysis of the Adhesive Remnant Index showed predominance of Score 5 .

\section{Collaborators}

MR PIAIA, AR COSTA, AB CORRER, L CORRERSOBRINHO, IU GARBUI and PRA NOUER participated in all the stages of writing the article.

10. Meyerson RL. Effects of silane bonding of acrylic resins to porcelain on porcelain struture. J Am Dent Assoc. 1969;78(1):113-9.

11. Paffenbarger GC, Sweeney WT, Bowen RL. Bonding porcelain teeth to acrylic resins denture bases. J Am Dent Assoc. 1967;74(5):1018-23.

12. Rosentiel SF, van Putten MC, Culbertson BM, Johnson MA. Titanates and zircoaluminates as coupling agents for dental cements. Int J Prosthodont. 1993;6(3):298-302.

13. Rueggeberg FA. Contemporary issues in photocuring. Compend Contin Educ Dent Suppl. 1999;(25):S4-25.

14. Brackett WW, Haisch LD, Covey DA. Effect of plasma arc curing on the microleakage of class $\mathrm{V}$ resin based composite restorations. Am J Dent. 2000;13(3):121-2.

15. Hasegawa T, Itoh K, Yukitani W, Wakumoto S, Hisamitsu $\mathrm{H}$. Depth of cure and Marginal adaptation of xenon lamp polymerized resin composites. Oper Dent. 2001;26(6):585-90.

16. Peutzfeldt A, Sahafi A, Asmussen E. Characterization of resin composites polymerized with plasma arc curing units. Dent Mater. 2000;16(5):330-6. doi: 10.1016/\$0109-5641(00)00025-7.

17. Pignatta LMB, Lugato ICPT, Bertoz FA, Santos ECA. Avaliação do índice de remanescente adesivo utilizando braquetes com e semtratamento na base e a interação com três sistemas de colagem. Rev Dental Press Ortod Facial. 2009;14(1):117-23. doi: 10.1590/S1415-54192009000100011.

18. Correr AB, Sinhoreti MA, Correr Sobrinho L, Tango RN, Schneider $L F$, Consani S. Effect of the increase of energy density on Knoop hardness of dental composites light-cured by conventional QTH, LED and xenon plasma arc. Braz Dent J. 2005;16(3):218-24. doi: 10.1590/S0103-64402005000300009.

19. Thind BS, Stirrups DR, Lloyd CH. A comparison of tungstenquartz-halogen, plasma arc and light-emitting diode light sources for the polymerization of an orthodontic adhesive. Eur J Orthod. 2006;28(1):78-82. 
20. Reynolds IR. Letter: composite filling materials as adhesives in orthodontics. Br Dent J. 1975;138(3):83.

21. Stewart GP, Jain $P$, Hodges J. Shear bond strength of resin cements to both ceramic and dentin. J Prosthet Dent. 2002;88(3):27784. doi: $10.1067 / \mathrm{mpr} .2002 .128034$.

22. Yoshida K, Yamashita M, Atsuta M. Bond strength between machinable glass-ceramic and dual-cured resin luting cements using silane coupling agents. Am J Dent. 2005;18(5):327-30.

23. Foxton RM, Nakajima $M$, Hiraishi $N$, Kitasako $Y$, Tagami J, Nomura S, et al. Relationship between ceramic primer and ceramic surface $\mathrm{pH}$ on the bonding of dual-cure resin cement to ceramic. Dent Mater. 2003;19(8):779-89. doi: 10.1016/S01095641(03)00026-5.
23. Yen TW, Blackman RB, Baez RJ. Effect of acid etching on the flexural strength of a feldspathic porcelain and a castable glass ceramic. J Prosthet Dent. 1993;70(3):224-33. doi: 10.1016/0022-3913(93)90056-T.

24. Canay S, Hersek N, Ertan A. Effect of different acid treatments on a porcelain surface. J Oral Rehabil. 2001;28(1):95-101. doi: 10.1046/j.1365-2842.2001.00626.x.

Received on: 17/12/2011

Final version resubmitted on: 15/3/2012

Approved on: 1/6/2012 